\title{
DOI: 10.1515/orga-2015-0017 \\ Sugar Beet Production: A System Dynamics Model and Economic Analysis
}

\author{
Črtomir Rozman ${ }^{1}$, Miroljub Kljajić² $^{2}$ Karmen Pažek ${ }^{1}$
}

\author{
${ }^{1}$ University of Maribor, Faculty of Agriculture and Life Sciences, Pivola 11, 2311 Hoče, Slovenia. \\ crt.rozman@um.si, karmen.pazek@um.si \\ ${ }^{2}$ University of Maribor, Faculty of Organizational Sciences, Kidričeva cesta 55a, 4000 Kranj, Slovenia. \\ miroljub.kljajic@fov.uni-mb.si
}

\begin{abstract}
Background and Purpose: The sugar beet is the main field crop used for sugar production in the temperate climatic zone. Since investment in sugar beet industry are long term and ireversible the decision support and economic analysis are required in order to maximise investment returns.

Methodology: A system dynamics methodology was chosen to model the impacts of regional sugar factory investments. We present the basic concepts of system dynamics (SD) models and their development in the case of sugar beet production and processing systems. Sugar beet economics are also analyzed using the static technological economic simulation model.

Results: The simulation provides answers to strategic questions related to the total sugar beet production and processing system and will be used for the simulation of different scenarios for sugar production and their impact on economic and environmental parameters at an aggregate level. Furthermore, the feasibility analysis of sugar beet production revealed that at the current price and intensity levels (yields), we can expect profitable sugar beet production for both white sugar and ethanol.

Conclusion: Preliminary results show that under expected production parameters the sugar beet processing and production would be economically feasible.
\end{abstract}

Keywords: sugar beet, modeling, system dynamics, economic feasibility

\section{Introduction}

The expected elimination of the sugar quota system in 2017 , in the final reform, presents new business opportunities for farmers and investors in countries that have abandoned sugar beet production and the sugar industry as a whole. However, the potential of a wide range of possible business alternatives must be evaluated in order to determine their obstacles and characteristics, and also the benefits with corresponding opportunities which they contribute to the agricultural system. The 2007 European Union (EU) Sugar Reform turned the EU from a major sugar exporter into a major sugar importer, significantly changing the dynamics of the EU sugar market. High international sugar prices have been undercutting the EU's attraction as a favored export destination, while the increased productivity resulting from the reform has led to record EU sugar production beyond the suggested quota (Polet, 2012).

The sugar beet is the main field crop used for sugar production in the temperate climatic zone. Approximately $30 \%$ of the world's supply of sugar is now derived from sugar beets (Beta vulgaris), the vast majority of which is produced in industrialized countries. The remaining $70 \%$ is derived from sugarcane, which is mainly produced in developing countries with tropical climates (Steinrücken, 2005).

According to Food and Agriculture Organization (FAO) data, the land area required for sugar beet production has decreased as a result of technical advances and higher yields (Steinrücken, 2005). The expected elimination of the sugar quota system in 2017, which is set out in the final reform, presents new business opportunities for farmers and investors in countries that have abandoned sugar beet production and the sugar industry as a whole. 
Since the investments in the sugar industry are long-term and financially demanding, there is a clear need for the use of modern decision support tools and models in order to ensure good decision support before the investment is made (Rozman et al., 2013a,b). However, drastically increasing energy costs and potential sugar trade policy reform threaten the viability of this important industry.

Currently, beet sugar refining byproducts are sold at very low margins. However, a large amount of research aimed at producing high-value goods from these byproducts has been conducted (USDA, 2007). In recent years, energy consumption and global carbon intensity (the ratio between carbon emissions and the amount of energy supplied) have increased worldwide, reinvigorating worries about potential depletion of fossil fuel reserves. Such an increase, accompanied by the growing political instability in oil-producing regions, has prompted many countries to search for alternative forms of energy (Martinelli \& Filoso, 2008). Sugar beet crops are grown in most EU countries and yield substantially more bio-ethanol per hectare than wheat. The advantages of sugar beets are a lower cycle of crop production, higher yield, high tolerance of a wide range of climatic variations, and low water and fertilizer requirements. Compared to sugar cane, sugar beets require $35-40 \%$ less water and fertilizer (Balat \& Balat, 2009). The development of ethanol production (from sugar cane) was first presented by $\mathrm{Hu}$ (2012). The system dynamics model applied here will require further research in order to generate insightful results regarding the Brazilian ethanol model. These results will be useful for the expansion of ethanol as a global commodity, as well as in tackling existing unintended consequences resulting from the development of this industry. Biofuels will continue to expand, but the feasibility of their exponential growth patterns remains questionable. The sustainability of the biofuel sector depends on the understanding of this social system, as well as its effect on other systems, such as the food economy.

The renewal of the sugar beet industry was examined in a feasibility study by Rozman et al. (2013a), who estimated the required technical parameters for a new sugar factory in order to achieve positive results in an investment analysis. The success of the industry is based on the economic achievement of all elements in the sugar production chain, where the sugar beet producers are the most important element. Thus, the economics of sugar beet production are essential for a successful sugar industry (Rozman et al., 2013a). Sugar beet economics have been closely studied by Tzilivakis, Jaggard, Lewis, May, and Warner (2005) and Maung and Gustaffson (2011), as well as by the Croatian, German, and Austrian Agricultural Advisory Extension Service.

Models of sugar factories have also been developed. Henke, Bubník, Hinková, and Pour (2006) described the application of the Sugars ${ }^{\mathrm{TM}}$ program to model and simu- late a sugar factory with subsequent production of bioethanol and animal fodder. The designed scheme was further adjusted and verified using data from the Czech sugar industry (i.e., 10,000 tons of sugar beets processed per day, $17 \%$ sucrose content in sugar beets, $2.5 \%$ impurities, and $98 \%$ effectiveness of ethanol fermentation). Rozman et al. (2013a) developed a spreadsheet technologic economic model for the feasibility analysis of the sugar beet plant. This model is used for the (1) assessment of sugar beet production costs, (2) sugar beet processing costs and factory cash flow projections, and (3) the complete analysis of the required field area necessary for the planned sugar factory. System dynamics (SD) is one of the possibilities for employing computer simulations in order to support the decision-making process in sugar beet processing (Forrester, 1994). The system dynamics was successfully applied in several similar cases (Rehan, Unger, Knight, \& Haas, 2014; Rozman et al., 2013a).

This paper discusses the problem of sugar beet economics and processing using causal loop diagram (CLD) and SD methodology for holistic decision support. The paper is organized as follows: first, we analyzed the entire sugar beet processing system using SD principles (causal loop diagram), followed by the analysis of sugar beet production economics. The article concludes with final remarks.

\section{System dynamics model of the sugar beet industry}

Several methods were used for the evaluation of a sustainable model for region planning development based on sugar production. First, we developed a system dynamic model based on the CLD at different scenarios that represents a different vision of development as well as multi criteria optimization based on the Saaty (1990) analytical hierarchical process (AHP). Such multi methodology is convenient to reflect the sustainable development of region. The fundamentals of system dynamics were defined by Forrester (1958) as a method for the modeling of industrial dynamics. In the early 1980 s, at the beginning of the Information Age, the method was renamed system dynamics (SD). The idea of this modeling is based on the assumption that every real system, as well as any business system, can be described with a system of equations that represent interconnected flows or Rates and Stocks or Levels.

Figure 2 provides an example of the SD symbolic representation of described model, in which for example Biological Residue represents the Levels (Stock), Beet Residue the input flow or Rate input, and Gas Power Plant the output flow or Rate output. Each level, $L$, or state element, has its own input rate, Rin, and its own output rate, Rout. In Figure 2 for example Desired Beet and Salary represent the decision parameters by which the flows are regulated. The clouds at the beginning and at the end represent the 
environment of the model. This is, therefore, our boundary for the modeling of the addressed model. From a formal viewpoint, this method is indeed straightforward and clear, as well as understandable. In the case of a concrete problem as this one, the possible meaning of both the $\mathrm{L}$ and $\mathrm{R}$ elements are obtained.

The conservation-of-mass principle for the above model could be described with the dynamics equation in the form of difference equation as follows:

$$
\begin{aligned}
& \text { Bio } R(k+1)=\text { Bio } R(k) \\
& +\Delta t(\text { Beet } R(k)-\text { GasPowerPlant }(k))
\end{aligned}
$$

in which $k$ represents discrete time and $\Delta \mathrm{t}$ is the time interval of computation. Each entrepreneur understands that the value of the Level element $\mathrm{L}(k+1)$ increases if $\operatorname{Rin}(k)$ $>\operatorname{Rout}(k)$; it is unchanged if $\operatorname{Rin}(k)=\mathrm{R}_{\text {out }}(k)$, and decreases if $\operatorname{Rin}(k)<\operatorname{Rout}(k)$.

Later on in the SD methodology, CLDs were added. CLDs are important for the determination of the model's structure and its parameters. CLDs include directed graphs with polarity. Each Level and Rate element has a directed arrow assigned so that one element represents the cause and the other the consequence. Directed arrows from the cause to the consequence have the "+" sign if both the cause and consequence have the same direction and "-" if the opposite direction exists. Another very important aspect of the SD methodology is the feedback loop. When several consecutive arrows in the CLD return to the initial element, as can be seen in Fig. 1, a closing path or a loop is created, which gives some feedback to the original element; therefore, it is called a feedback loop. There are two kinds of feedback loops: a positive feedback loop (reinforcing loop) and a negative feedback loop (balancing loop). Reinforcing loops tend to grow or decline without limits and can make the system unstable. In contrast, balancing loops tend to adjust themselves to some intended value. Hence, they tend to stabilize the system and guide it to the goal.

The method for problem solving with a system dynamics methodology is similar to that used with the systems approach, and it can be described as a synthesis of the following steps:

- Definition of the problem

- Setting objectives

- Drafting the study

- Formulation of a mathematical model

- Developing a computer program

- Model validation

- Preparation of the experiment (simulation scenario)

- Simulation with an analysis of the results (Forrester, 1994)

In this study, we followed these steps to develop the simulation model of sugar factory development, which will be presented in detail in the next sections.

As stated in the introduction, the investment in new sugar beet processing factories has many advantages for a region: tradition, culture, land availability, and unemployment. However, due to the effects of the financial crisis and the impacts on ecology, a local authority must consider a number of factors in addition to economics when planning future development. Therefore, we decided to use SD methodology for such analyses as one powerful method of decision support. Figure 1 shows a causal loop diagram (CLD) of a new sugar production factory with all relevant implications for development in the region. We can observe several main feedback loops reinforcing and balancing in Figure 1. The reinforcing loops R1, R2, R3, and $\mathrm{R} 4$ are typical developmental loops. The investment in sugar production represents a new employment opportunity and increases workforce demand. Therefore, investment in the sugar factory, ethanol factory, and power from the electrical biogas-based power plant will provide new employment opportunities and workforce demand in the sugar production and electrical plant sectors, which has a final impact on regional development for some time following the investment.

This impact is also evident in the demand for special agricultural custom machine services, such as sugar beet harvesting, cleaning-loading, and transport. The sugar industry also contributes to employment in other sectors that support the sugar industry with production inputs (such as the use of lime and fuel), as well as input for sugar beet production in the field. According to Rozman et al. (2013a), a factory with a capacity for 7500 tons of beets/ day requires around 30 full-time equivalents (FTE) during the campaign for transport alone. Of course, this figure depends on the market prices of both sugar and electricity. However, the new sugar or bioethanol plant requires land for sugar beet production. Therefore, available land for field crop production is decreased, which influences the capacity of the new plant (balancing loop B3). The sugar beet production area is limited by crop rotation rules. The recommended share of sugar beets in the crop rotation is $20 \%$; higher shares can cause a decrease in yields and sugar content and may also lead to more serious pest problems. There is also balancing loop B2 with a variable sugar price, which influences the decision-makers. Namely, the higher sugar production consequently increases the market surplus and lowers the price of sugar. When this scenario is occurs, the use of beets for bioethanol increases.

Increased sugar production and/or the import of sugar from a free market leads to a decrease in the price of sugar, which can negatively impact farmers' motivation to grow sugar beets and consequently result in a decrease of land for the sugar crop area and also a decreased production level. The B2 and B3 loops are the basis for the planning of the potential capacity of both plants. Biological remains (such as green mass and soil that come to the factory with 


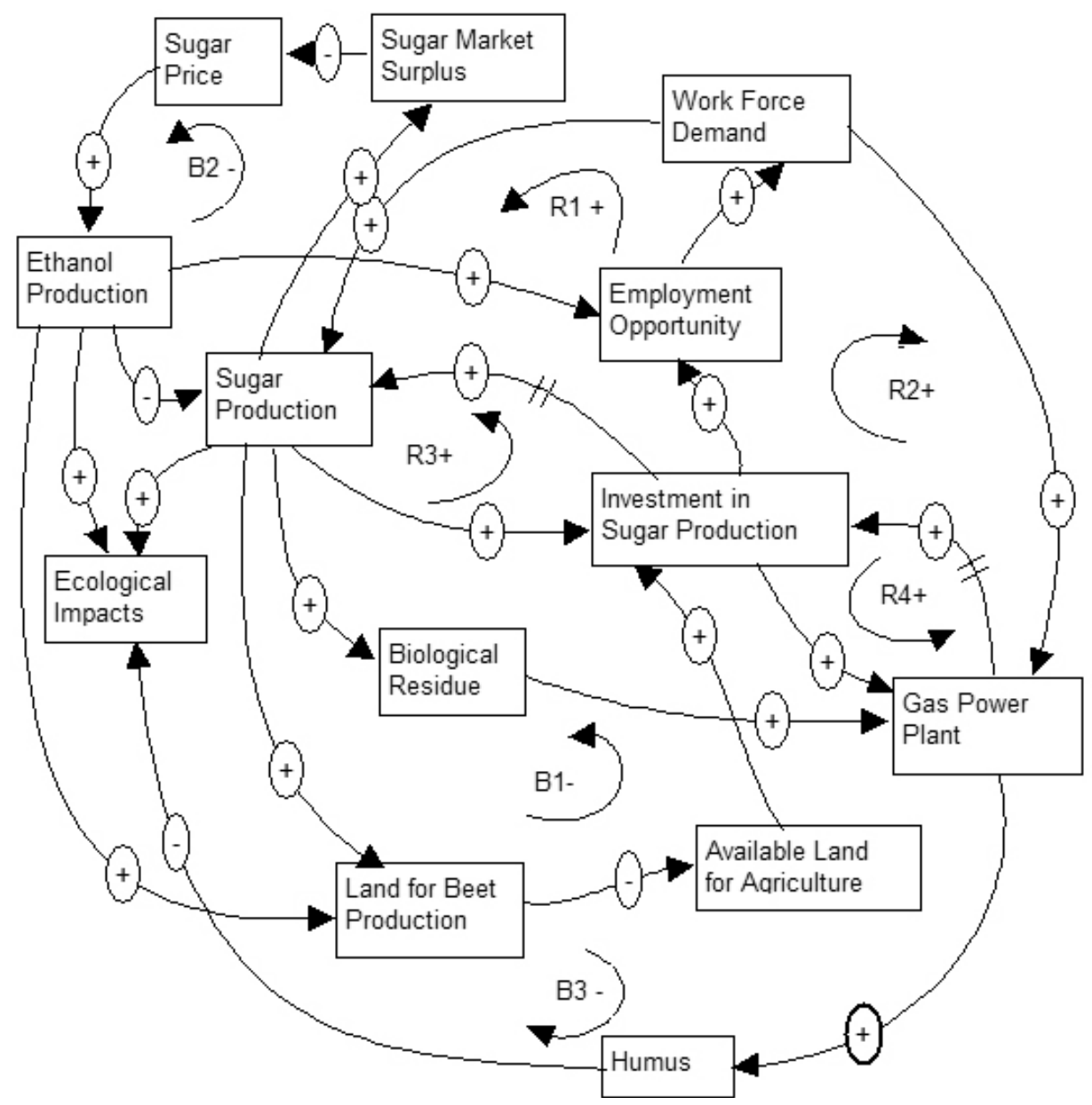

Figure 1: Holistic model of regional development of the new product (sugar and bioethanol)

the beets) can affect the environment; therefore, a biogas plant that produces electric energy and additional employment opportunities should be constructed. In this manner, the negative influence on the environment is decreased (balancing loop B1). The reduction of the negative effect on the environment through loop B1 is also expressed in the use of waste lime, which is produced as a result of the carbonation sugar-cleaning process in one of the stages of sugar production. Waste lime is one of the most effective lime-based fertilizers and, importantly, its use by sugar beet producing farmers contributes to a decrease in soil acidity.

The remains from the biogas plant can also be used as fertilizer. Furthermore, biogas production is usually combined with liquid manure from animal farms. Liquid manure is the source of methane $\left(\mathrm{CH}_{4}\right)$, which is an even more damaging greenhouse gas than carbon dioxide $\left(\mathrm{CO}_{2}\right)$. In the biogas plant, the $\mathrm{CH}_{4}$ (produced through methagenic fermentation in the biogas plant reactor) is transformed to less damaging carbon dioxide and water in the gas engine that powers the electric generator. Figure 1 is qualitative and displays important causal loop relationships between relevant factors when choosing an investment. This information can be incorporated into the holistic model in Figure 1; however, several other elements must be considered in further model development, such as annual climatic factors, world sugar production, and price. This paper discusses the problem of sugar beet processing using CLDs; SD methodology for holistic decision support was previously described (Rozman et al., 2014a).

Figure 2 shows the SD model of the sugar beet industry and its impact on the environment as well as on the workforce in local communities. We used the standard stock-inventory model as a basis (Forrester, 1994). The primary driving variable in the model is demand, which determines the operation of the entire system. According to the demand, the sales diminish the sugar stock. In contrast, the demand influences the desired production. One may observe the delay from demand to desired beet and row material is at least one year and is relevant for the 
process behavior. Another link that influences desired beet and sugar stock is the sugar price, which was included in this model as the average market value. The sugar beet stock is dependent on the sugar beet delivery, which increases the sugar beet stock. Conversely, the intensity of the production decreases the sugar beet stock. The sugar stock is therefore dependent on the production, as well as on the capability to provide a sufficient sugar beet stock supply. The structure represents a negative feedback loop with reference, which is primarily determined by the sugar demand. The financial aspects of a new investigation were modeled in Powersim software as a continuous simulation

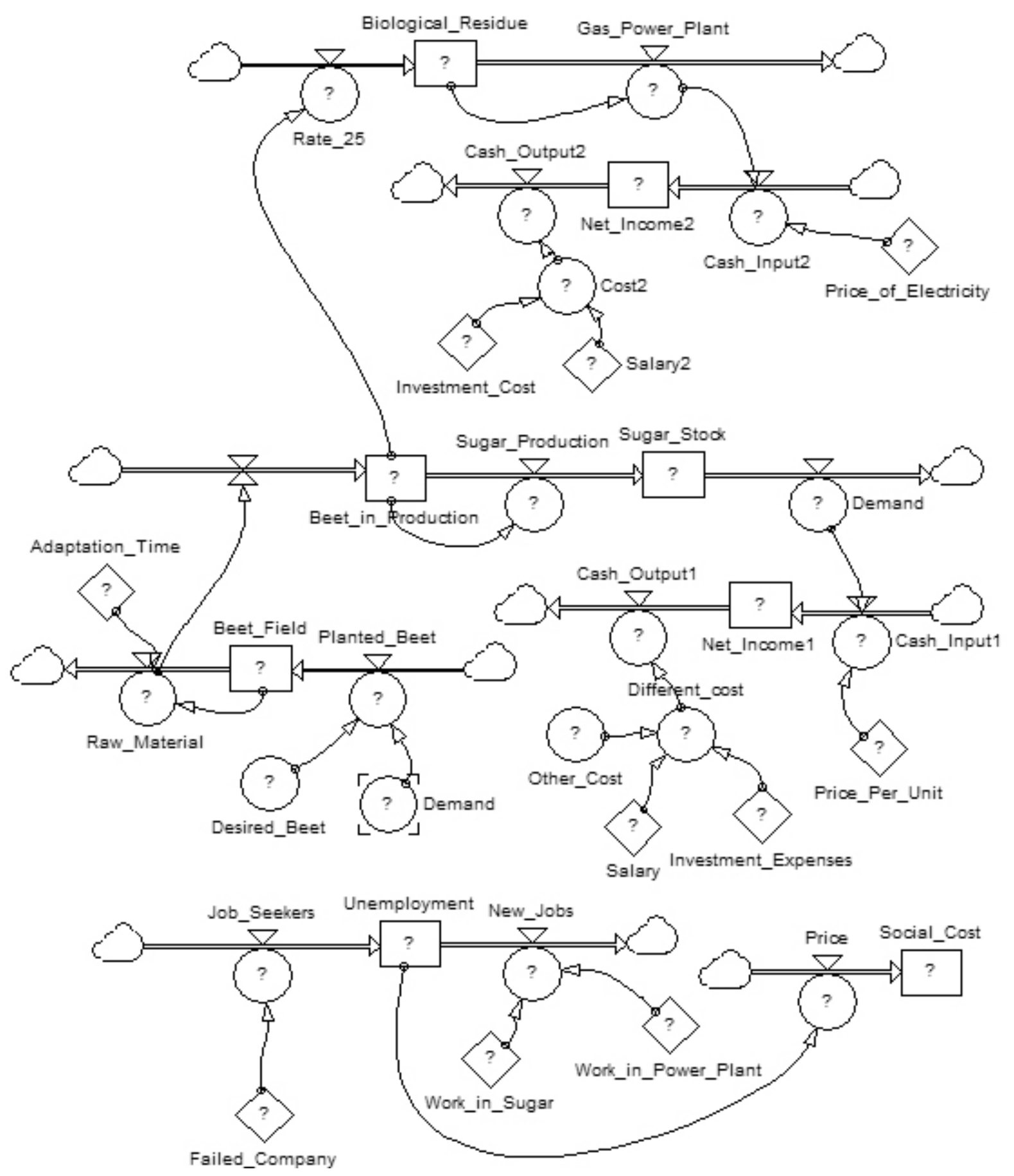

Figure 2: The preliminary SD model to support investment decisions 
model based on SD methodology. The model will be used to test different business strategies in order to define the appropriate mixture of price and costs for anticipated market demand with respect to production constraints. However, the main variables for regional decision-makers were the net incomes, as follows: Net Income1, which represents the financial aspect of sugar production, and Net Income2, which represents the financial aspect of gas electrical production and social transfer cost.

$$
\begin{aligned}
& B P(k+1)=B P(k)+\Delta t(R M(k)-S P(k)) \\
& S S(k+1)=S S(k)+\Delta t(S P(k)-D(k)) \\
& B F(k+1)=B F(k)+\Delta t(P B(\varphi(D, D B))-R M(k) \\
& B i o R(k+1)=B i o R(k)+\Delta t(\operatorname{BeetR}-G P P(k)) \\
& U(k+1)=U(k)+\Delta t(J S(k)-N J(k)) \\
& N I_{1}(k+1)=N I_{1}(k)+\Delta t\left(D(k) * C_{1}-C O_{1}(k)\right) \\
& N I_{2}(k+1)=N I_{2}(k)+\Delta t\left(G P P(k) * C_{2}-C O_{2}(k)\right) \\
& S C(k+1)=S C(k)+\Delta t\left(U(k) * C_{3}\right)
\end{aligned}
$$

Where of Level in equation (2) means; BP $(\mathrm{k})=$ Beet in Production, SS $(\mathrm{k})=$ Sugar Stock, BF $(\mathrm{k})=$ Beet Field, BioR $(\mathrm{k})=$ Biological Residue, $\mathrm{NI}_{1}(\mathrm{k})=$ Net Income of Sugar, $\mathrm{NI}_{2}(\mathrm{k})=$ Net Income of Gas Power Plant, and SC $(\mathrm{k})=$ Social Cost.
Flow elements: $\mathrm{RM}=$ Row Material, $\mathrm{PB}=$ Planted Beet, $\mathrm{SP}=$ Sugar Production, $\mathrm{D}=$ Demand, $\mathrm{DB}=$ Desired Beet, BeetR $=$ Beet Residue/per time, GEP $=$ Gas Power Plant, JS $=$ Job Seekers, New Job $=$ Number of Sugar Workers + Workers in Gas Power Plant and $\mathrm{C}_{1}=\mathrm{D}(\mathrm{k})^{*}$ Price per Unit, $\mathrm{C}_{2}=$ Gas Power Plant*Price of electricity, $\mathrm{CO}_{1}=$ Investment cost, Salary and Other cost, $\mathrm{CO}_{2}=$ Investment cost + Salary and $\mathrm{U}(\mathrm{k}) * \mathrm{C}_{3}=$ Number of Unemployment $*$ Average salary of unemployment.

In equation (2) for simplicity we use first character of capital words in assignment of equation notation.

\section{Economic feasibility of sugar beet production}

For the financial and technological analysis of the sugar beet production on Slovenian farms, an integrated deterministic computer process simulation was developed for the purpose of conducting a sugar beet renewal feasibility study. The model consists of various sub-models that represent each segment of the sugar beet growing process. The sub-models are based upon deterministic technologic economic simulation (Csaki, 1985; Rozman et al., 2002), where the technical relations in the system are expressed with a set of equations or with functional relationships.

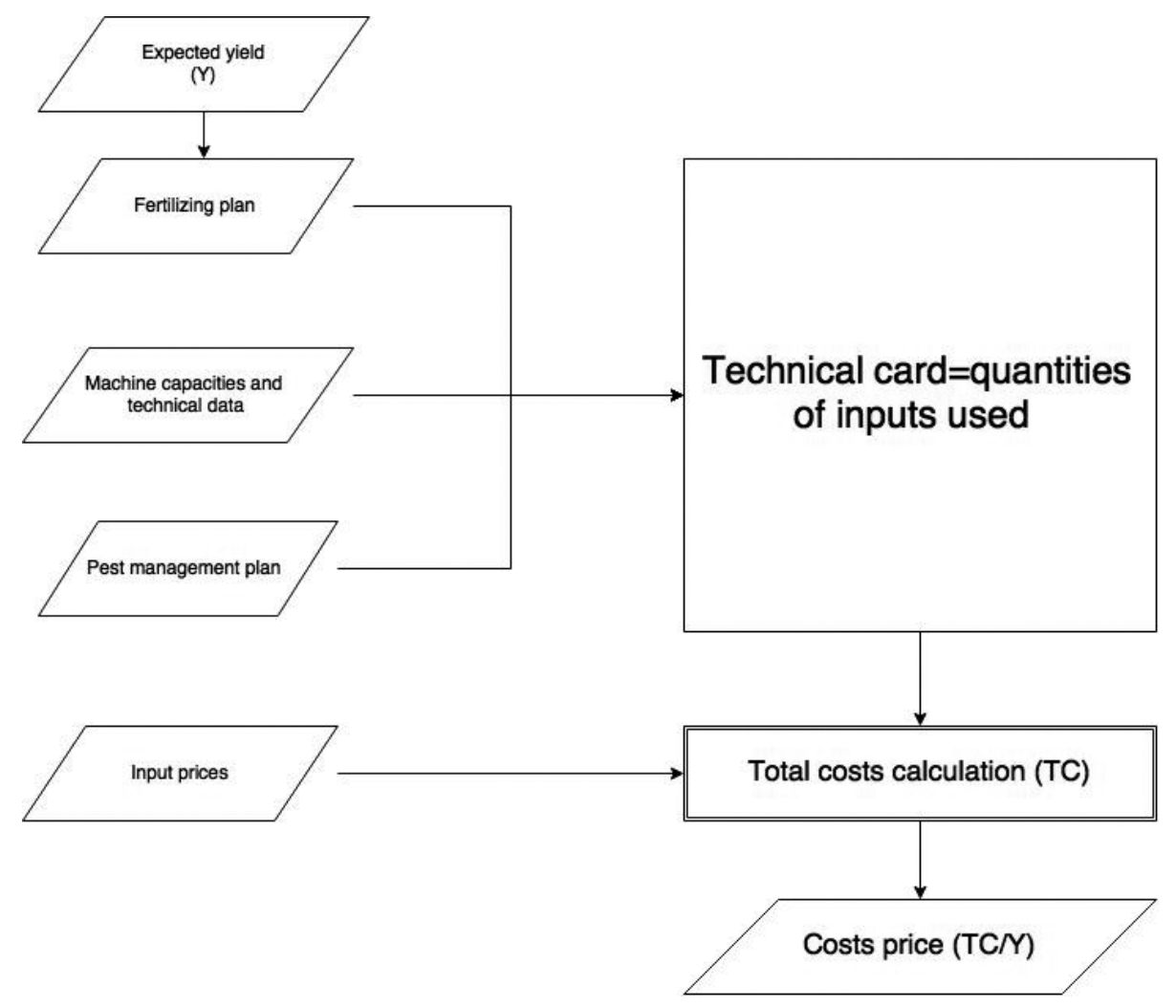

Figure 3: Main elements of the sugar beet production process model 
The amount of inputs used was calculated as a function of the given production intensity, while the production costs are ultimately calculated as dot products between the model's estimated inputs' usage and their prices. The model structure is shown in Figure 3.

The system as a whole represents a complex calculation system, and each sub-model indicates in a specific sub-calculation. Through a special interface, the system enables simulation of different alternatives at a farm level. All iterations (calculations for individual alternatives) are saved in a database and can be used for further analysis. The simulation system is constructed in an Excel spreadsheet environment and upgraded with Visual Basic code in order to ensure better functionality of a user-friendly calculation system.
Using this model, we simulated different production scenarios in order to assess the cost price, which is calculated as follows:

$$
\mathrm{CP}=\mathrm{TC} / \mathrm{Y}
$$

where:

- CP: cost price $(€ / t)$

- TC: total costs $(€ / \mathrm{ha})$;

- Y: expected yield (t/ha).

A comparison of the cost price and market price is used to estimate the economic feasibility of sugar beet production. We used five different yields levels both with irrigation and without irrigation (Table 1).

Table 2 shows the sugar beet market prices for white sugar in the region for 2014.

Table 1: Cost price of sugar beets

\begin{tabular}{|c|c|c|c|}
\hline \multicolumn{2}{|c|}{$\begin{array}{c}\text { With } \\
\text { irrigation }\end{array}$} & \multicolumn{2}{c|}{$\begin{array}{c}\text { Without } \\
\text { irrigation }\end{array}$} \\
\hline Yield & $\begin{array}{c}\text { Cost price } \\
\mathrm{f} / \mathrm{t}\end{array}$ & $\begin{array}{c}\text { Yield } \\
\mathrm{t} / \mathrm{ha}\end{array}$ & $\begin{array}{c}\text { Cost price } \\
€ / \mathrm{t}\end{array}$ \\
$\mathrm{t} / \mathrm{ha}$ & 28.92 & 50 & 30.12 \\
60 & 26.62 & 55 & 27.79 \\
66 & 24.69 & 60 & 25.85 \\
72 & 23.07 & 65 & 24.20 \\
78 & 21.67 & 70 & 22.79 \\
\hline
\end{tabular}

Table 2: Expected market prices for sugar beets (white sugar) in the region

\begin{tabular}{|c|c|c|}
\hline Country & Market price $(€ /$ t) from 2009-2013 & Market price $(€ /$ t) from 2014 \\
\hline Germany & 48.7 & 36.7 \\
\hline Austria & 51.4 & N/A \\
\hline Croatia & $46.18(2012)$ & 31.69 \\
\hline
\end{tabular}

Table 3: Expected market prices for sugar beets (ethanol) in the region

\begin{tabular}{|c|c|c|}
\hline Country & Market price $(€ /$ t) from 2009-2013 & Market price $(€ /$ t) from 2014 \\
\hline Germany & 33.2 & 25.5 \\
\hline Austria & 36.7 & 36.8 (in 2013) \\
\hline
\end{tabular}

Table 4: Break-even yields for different sugar beet prices

\begin{tabular}{|c|c|c|c|}
\hline Price $(€ / \mathrm{t})$ & 25 & 30 & 45 \\
\hline Break even yield (t/ha) & 63.81 & 53.18 & 35.45 \\
\hline $\begin{array}{c}\text { Break even yield with irrigation } \\
(\mathrm{t} / \mathrm{ha})\end{array}$ & 64.63 & 50.44 & 40.46 \\
\hline
\end{tabular}


Based on Table 2, we can observe that the calculated cost prices are below the market prices of beets used to produce white sugar. Therefore, sugar beet production is economically feasible assuming that the expected production parameters (yield) are achieved. In the case of beets used for bioethanol, the expected market price is around $27 € / \mathrm{t}$. As a result, the sugar beet grower must achieve higher yields in cases of bioethanol production.

We can also calculate the break-even yield (BEY) as a coefficient between the total costs and the expected price. For the BEY, the net return for the farmer is zero. The BEYs are shown in Table 4.

The historical data (Rozman et al., 2013a) and current production data from the region (Germany, Austria, and Croatia) indicate that the BEY has been exceeded.

\section{Results and discussion}

The decision problem of the model (2) could be considered as follows: Max expected utility of the criteria function equation (4).

$$
\begin{aligned}
& J=\operatorname{Max}\left(N I_{j}(k)+N I(j-1)(k)-S C(k)\right) \\
& \text { for } j=1,2
\end{aligned}
$$

where $\mathrm{j}=1$ indicates investment only in Sugar production and $\mathrm{j}=2$ stands for an investment in Sugar production + Gas power plant. The Social Cost variable is cumulative and could be present in equation (4) for both scenarios $j=1,2$. However, the main scenarios should be created according to variables $\varphi(\mathrm{D}, \mathrm{DB})$ in equation (2) defined as follows:

$\varphi(\mathrm{D}, \mathrm{DB})=\varphi($ Demand, Desired Beet, Price of Sugar, Existing Crop Rotation, Bioethanol, Electrical price, etc.)

Equation (5) represents the global scenarios for decision-makers in regards to regional planning. An expert group should determine the unit sale price and market demand function, according to the different production scenarios and properties of the alternatives. In fact, investigations exist in the mentioned region in separate subsystems for the electrical power plant based on organic residue. However, many of the installed parts do not work properly.

With investment in the sugar factory and adequate organization of existing parts in the systems, it is possible to create satisfactory functioning in the local community in an economic, ecological, and employment sense. This task has to be negotiated at a local and also a government level, and it is the most difficult task. According to an economic analysis of the investment in the previous paragraph and the CLD model expert group considered utility of investigation by multi criteria decision-making.

Alternatives are analyzed according to the AHP methods (Saaty, 1990) as a multi criteria decision. The set of criteria (Net Income, Ecology, Social Cost, and Investment Risk) along with its weights $(0.522,0.200,0.078$, and 0.200 ) were respectively considered. The weights of the Values of Net income criterion for AHP assessment were estimated using Equation 4. Namely, the failed company resulted in new unemployment, which created a higher expense for the government for social transfer. However, the new investment could also reduce the number of social transfers by employment in a new industry. A similar concept of sectorial policy reforms was considered in Gohin and Bureau (2006).

The set of alternatives (Sugar, Sugar + Biogas, Existing Crop Rotation Sugar + Bioethanol) along with their weights was determined for each criterion. Based upon the group decision of experts, we obtained a range of alternatives with their weighting as follows:

- Sugar + Biogas $=0.418$

- Sugar + Bioethanol $=0.263$

- Sugar $=0.172$

- Existing Crop Rotation $=0.147$

Therefore, the most attractive alternative, at the moment of decision, was Sugar + Biogas. However, the developed model enables the management of a local community the chance to easily control the type of regime of the systems without influencing employment or ecology and without requiring any additional investigation.

\section{Conclusions}

In this paper, we employed a preliminary SD model to simulate the sugar beet processing method. The presented SD model enables the modeling of different policies, and it is comprehensible to a wide range of users who are involved in the decision-making process. The holistic model presented the main feedback loops and dynamics of the main elements in the case of regional investment in the sugar industry. In addition to negative feedback loops that keep some parameters in equilibrium (price, sugar beet production area), there are also important reinforcing feedback loops that promote the social and ecological impacts of a sugar beet production system.

In this way, we can simulate the effects of the investment in a sugar factory on the regional economy (workforce) and environment. This way we can simulate the effects of the investment in a sugar factory on the regional economy (work force) and environment. Further consideration must be given to the interaction between elements in the main feedback loop in the system, which determines the system performance and provides the means for proper definition of control strategy.

Furthermore, we analyzed sugar beet production economics using a spreadsheet process simulation model with different production parameters. According to current sugar beet market prices and expected yields, we can 
expect economically feasible sugar beet production. The multi-criteria AHP analysis showed that sugar and biogas is the most suitable alternative for investment planning.

\section{Acknowledgement}

This research was supported by Sugar Beet Growers Association of Slovenia (contract No. 1/2012).

\section{Literature}

Balat, M., \& Balat, H. (2009). Recent trends in global production and utilization of bio-ethanol fuel. Applied energy, 86(11), 2273-2282, http://dx.doi.org/10.1016/j. apenergy.2009.03.015

Csaki, C. (1985). Simulation and system analysis in agriculture. Amsterdam: Elsevier.

Federal Institute of Agricultural Economics. (n.d.). AWIDeckungsbeiträge und Kalkulationsdaten-Zuckerrüben. Retrieved from http://www.awi.bmlfuw.gv.at/idb/ zuckerrueben.html

Forrester, J. W. (1994). System dynamics, systems thinking, and soft OR. System Dynamic Review, 10(2-3), 245-256, http://dx.doi.org/10.1002/sdr.4260100211

Gohin, A., \& Bureau, J. C. (2006). Modelling the EU sugar supply to assess sectoral policy reforms. European Review of Agricultural Economics, 33(2), 223-247, http://dx.doi.org/10.1093/erae/jbl006

Henke, S., Bubník, Z., Hinková, A., \& Pour, V. (2006). Model of a sugar factory with bioethanol production in program Sugars ${ }^{\mathrm{TM}}$. Journal of Food Engineering, 77(3), 416-420, http://dx.doi.org/10.1016/j.jfoodeng.2005.07.007

$\mathrm{Hu}$, O. (2012). System Dynamics Modeling of the Brazilian Sugarcane Ethanol Industry. Retrieved from http://computationalmodelingblogs.stanford.edu/ winter2012/2012/03/25/system-dynamics-modeling-of-the-brazilian-sugarcane-ethanol-industry/

Kalkulacije pokrića ratarskih kultura (n.d.).. [Gross margin calculation for field crops]. Retrieved from http:// www.savjetodavna.hr/adminmax/File/Katalog_kalkulacija 2012/Kalkulacije 2012 ratarstvo.pdf

Martinelli, L. A., \& Filoso, S. (2008). Expansion of sugarcane ethanol production in Brazil: Environmental and social challenges. Ecological Applications, 18(4), 885-898, http://dx.doi.org/10.1890/07-1813.1

Maung, T. A., \& Gustafson, C. R. (2011). The economic feasibility of sugar beet biofuel production in central North Dakota. Biomass and Bioenergy, 35(9), 3737-3747, http://dx.doi.org/10.1016/j.biombioe.2011.05.022

Polet, Y. (2012). EU 27 sugar annual report 2012. USDA Foreign Agricultural Service. Retrieved from http:// gain.fas.usda.gov/Recent\%20GAIN\%20Publications/
Sugar\%20Annual_Brussels\%20USEU_EU-27_4-272012.pdf

Rehan, R., Unger, A. J. A., Knight, M. A., \& Haas, C. T. (2014). Financially sustainable management strategies for urban wastewater collection infrastructure-Implementation of a system dynamics model. Tunnelling and Underground Space Technology, 39, 102-115, http://dx.doi.org/10.1016/j.tust.2012.12.004

Rozman, C., Tojnko, S., Turk, J., Par, V., \& Pavlovic, M. (2002). Die Anwendung eines Computersimulationsmodells zur Optimierung der Erweiterung einer Apfelplantage unter den Bedingungen der Republik Slowenien. Berichte uber Landwirtschaft-Hamburg, 80(4), 632-644.

Rozman, Č., Kljajić, M., \& Pažek, K. (2014a). Integral approach to development of sugar beet production to support decision-making processes. In M. Kljajic \& G. E. Lasker (Eds.), Advances in simulation-based decision support and business intelligence (Vol. 4, p. 6). Tecumseh, Ontario, Canada: International Institute for Advanced Studies in Systems Research and Cybernetics.

Rozman, Č., Pažek, K., Kljajić, M., Bavec, M., Turk, J., Bavec, F.,Škraba, A. (2013). The dynamic simulation of organic farming development scenarios-A case study in Slovenia. Computers and Electronics in Agriculture, 96, 163-172, http://dx.doi.org/10.1016/j.compag.2013.05.005

Rozman, Č., Pažek, K., \& Petek, J. (2013). Študija izvedljivosti projekta pridelave in predelave sladkorne pese [Feasibility study of sugar beet production and processing]. Hoče: University of Maribor, Faculty of Agriculture and Life Sciences. Retrieved from http:// www.sladkornapesa.si/dmdocuments/Studija\%20 o\%20izvedljivosti\%20projekta.pdf

Rozman, Č., Škraba, A., Pažek, K., \& Kljajić, M. (2014b). The development of sugar beet production and processing simulation model-A system dynamics approach to support decision-making processes. Organizacija, 47(2), 99-105, http://dx.doi.org/10.2478/ orga-2014-0011

Saaty, T. L. (1990). How to make a decision: the analytic hierarchy process. European Journal of Operational Research, 48(1), 9-26, http://dx.doi.org/10.1016/03772217(90)90057-I

Schätzl, R., Weber, J. T., Schägger, M., \& Frank, J. (2015). Bavarian State Research Center for Agriculture. LfL-Deckungsbeiträge und Kalkulationsdaten - Zuckerrüben. Retrieved from https://www.stmelf.bayern. de/idb/zuckerrueben.html

Steinrücken, G. (2005). Prospects in sugar beet breeding. In E. Biancardi, L. G. Campbell, G. N. Skaracis, \& M. De Biaggi (Eds.), Genetics and breeding of sugar beet (pp. 309-323). Enfield, NH: Science Publishers, Inc.

Tzilivakis, J., Jaggard, K., Lewis, K. A., May, M., \& War- 
ner, D. J. (2005). Environmental impact and economic assessment for UK sugar beet production systems. $\mathrm{Ag}$ riculture, Ecosystems \& Environment, 107(4), 341358, http://dx.doi.org/10.1016/j.agee.2004.12.016

Watts and Associates, Inc. (2007). Alternative sugar beet byproduct uses research and feasibility analysis. Retrieved from http://www.ams.usda.gov/AMSv1.0/getfile?dDocName $=$ STELPRDC5058621

Črtomir Rozman conducted his postgraduate studies at University of Zagreb and achieved his Ph.D. at University of Maribor, Faculty of Agriculture. He is active as Full Professor for Farm management in the Department for Agriculture Economics and Rural Development (Faculty of Agriculture and Life Sciences, University of Maribor). His research includes development of decision support systems for farm management (simulation modeling, multi criteria decision analysis, machine learning) and economics of agricultural production. He is also involved in teaching activities and as thesis supervisor at post graduate study programs and multiple national and international research projects. He is author or coauthor of 69 scientific papers including 28 papers in journals with impact factor.
Karmen Pažek achieved her Ph.D. at University of Maribor, Faculty of Agriculture in 2006. She is active as Associated Professor for Farm management in the Department for Agriculture Economics and Rural Development on Faculty of Agriculture and Life Sciences, University of Maribor. Her research includes development of decision support tools and systems for farm management (simulation modeling, multicriteria decision analysis, option models) and economics of agricultural production. She is involved in teaching activities as thesis supervisor at postgraduate study programs and involved in national and international research projects. She is author or coauthor of 41 scientific papers including 20 papers in journals with impact factor.

Miroljub Kljajić completed his Ph.D. at the Faculty of Electronics, University of Ljubljana in 1974. He is a Professor Emeritus at the Faculty of Organizational Sciences in Kranj in the area of Systems Theory, Cybernetics and Computer Simulation. His main fields of research include decision support systems in global e-commerce and methods of modeling and simulation of organizational systems. He has been the principal investigator of many national and international modeling and simulation projects. As author and co-author, he has published more than 40 scientific articles recognized in $\mathrm{SCl}$ with more than 400 citations. 